\title{
Pediatric Intestinal Obstruction, Management and Outcomes: A Simple Literature Review
} Alaa Mutlaq Alshareef ${ }^{1}$, Shahd Saeed Alghaseb ${ }^{2}$, Lamia Saeed Alghaseb $^{2}$, Shahad Ahmed
Alqahtani $^{2}$, Norah Fahad Alshahrani ${ }^{2}$, Norah Abdullah Hasoosah
Marwah Nasser E Alabdrabalameer $^{3}$, Alia Musfer Alqahtani
${ }^{2}$,

\author{
${ }^{1}$ Ibn Sina National College, ${ }^{2}$ King Khalid University, ${ }^{3}$ Maastricht University, ${ }^{4}$ Najran University, \\ ${ }^{5}$ Shaqra University
}

\begin{abstract}
Background: Acute intestinal obstruction occurs when there is an interruption in the forward flow of intestinal contents. This interruption can occur at any point along the length of the gastrointestinal tract, and clinical symptoms often vary based on the level of obstruction. Intestinal obstruction in children can occur as a result of various causes such as, intussusception, adhesive small bowel obstruction, malrotation, and Hirschsprung's disease. In this review paper we will go through the literatures that have been investigated to assess the various management measures and its outcomes.

Objective: In this review we aimed at assessing of different management plans of gastrointestinal obstruction in different conditions like Intussusception, Congenital Duodenal Obstruction and Adhesive Small Bowel Obstruction (ASBO), and the outcomes related. Moreover, providing a reference paper analyzing all the clinical studies in this field.

Methods: PubMed database was used for articles selection, and the following keys used in the Mesh ("Intestinal Obstruction/diet therapy"[Mesh] OR "Intestinal Obstruction/drug effects"[Mesh] OR "Intestinal Obstruction/ drug therapy"[Mesh] OR "Intestinal Obstruction/surgery"[Mesh] OR "Intestinal Obstruction/ therapy"[Mesh]).

Results: Intussusception should be treated with hydrostatic reduction (HR) even with more than one try because this method was associated with high success rate. After successful HR, patient can be discharged from ED if there were no suspected complications. Surgical treatment is indicated mostly in cases of complications. Manual reduction was associated with significantly better post-operative outcomes and lesser time to recovery. It is advised not to maintain high threshold for resection in order to avoid post-operative recurrence or perforation. The use of Gastrografin in treating children with adhesive small bowel obstruction when the conservative management fails is safe. However, half of the patients will need surgical management after all.

Conclusion: The laparoscopic approach in the management of congenital duodenal obstruction can be performed in neonates safely. It showed similar outcomes to the open approach despite the presence of high conversion rate.
\end{abstract}

Keywords: Pediatric intestinal obstruction, congenital duodenal obstruction, gastrografin, laparoscopic approach.

\section{INTRODUCTION}

Gastrointestinal obstruction occurs when the intestinal content flow is interrupted. The interruption can occur at any point throughout the gastrointestinal tract. The obstruction presentation depends on the level of obstruction. Intestinal obstruction can occur as a result of various cause, and most of the time present as a medical emergency $^{(1)}$. As a result physicians should early recognize such cases and provide the appropriate management. Acute intestinal obstruction is associated with nausea, vomiting, dysphagia, abdominal pain and failure to pass bowel movements ${ }^{(2)}$. To approach the diagnosis certain tests can be done such as radiography, ultrasonography, and contrast fluoroscopy and computer tomography in less certain cases ${ }^{(2)}$.
Despite advances in neonatal and surgical care, the management of gastrointestinal obstruction is challenging. A surgeon should decide wither to take the patient for open or laparoscopic surgery or follow a non-operative treatment. In this paper we focused upon reviewing the management, and outcome of gastrointestinal obstruction in children.

\section{Pathophysiology}

The most important concerns in relation to intestinal obstruction are their effect on whole body fluid/electrolyte balances and the mechanical effect that increased pressure has on intestinal perfusion. Proximal to the point of obstruction, there will be a dilatation of the intestinal tract as a result of intestinal secretions and swallowed $\mathrm{air}^{(3)}$. As a result of the obstruction the intestinal content will fail to pass which will lead to cessation of flatus and bowel movements. 
Patients presented with intestinal obstruction are at high risk of dehydration development as a result of emesis, bowel edema, and loss of absorptive capacity. Emesis is associated with loss of gastric potassium, hydrogen, and chloride ions, and dehydration. As a result of these consequences renal proximal tubule reabsorption of bicarbonate occurs associated with loss of chloride, perpetuating the metabolic alkalosis ${ }^{(4)}$. In addition to the imbalance in the body fluid electrolytes, the intestinal stasis is associated with overgrowth of intestinal flora that may lead to more episodes of emesis ${ }^{(5)}$.

Due to the above prescribed process, the intestinal luminal pressure will increase until exceed the venous pressure, which will cause blockage of venous drainage, increasing edema and hyperemia of the bowel. This may eventually lead to compromised arterial flow to the bowel, causing ischemia, necrosis, and perforation. A closed-loop obstruction, in which a section of bowel is obstructed proximally and distally, may undergo this process rapidly, with few presenting symptoms.

\section{METHODOLOGY}

\section{Sample}

PubMed was chosen as the search database for the articles selection, because it is one of the major research databases within the suite of resources that have been developed by the National Center for Biotechnology Information (NCBI). The following keys used for the Mesh ("Intestinal Obstruction/diet therapy" [Mesh] OR "Intestinal Obstruction/drug effects" [Mesh] OR "Intestinal Obstruction/drug therapy"[Mesh] OR "Intestinal Obstruction/ surgery "[Mesh] OR "Intestinal Obstruction/ therapy"[Mesh]). Inclusion criteria, the articles were selected based on the relevance to the project which should include one of the following topics, \{Gastrointestinal Obstruction, Management, Outcomes, Mortality \& Morbidity\}. Exclusion criteria, all other articles which did not have one of these topics as their primary end point, or repeated studies.

\section{Analysis:}

No software was used, The data were extracted based on specific form that contain (Title of the study, name of the author, Objective, Summary, Results, and Outcomes). These data were reviewed by the group members to assess different management plans of intestinal obstruction, and the outcomes related. Double revision of each member's outcomes was applied to ensure the validity and minimize errors.

\section{RESULTS}

Table (1): The included Studies.

\begin{tabular}{|c|c|c|c|c|c|c|}
\hline $\begin{array}{l}\text { Study } \\
\text { (year) }\end{array}$ & Design & Country & Objective & $\begin{array}{c}\text { Participants } \\
\text { (n) }\end{array}$ & $\begin{array}{c}\text { Duration } \\
\text { (years) }\end{array}$ & Outcome and Conclusion \\
\hline $\begin{array}{l}\text { Vujovi et } \\
\text { al. }^{(6)}\end{array}$ & Retrospective & Serbia & $\begin{array}{c}\text { Evaluation of the influence of } \\
\text { symptom duration in non- } \\
\text { operative treatment, considering } \\
\text { the indications for delayed enema } \\
\text { reduction and its efficacy }\end{array}$ & 107 & 17 & $\begin{array}{l}\text { The accuracy of ultrasound guided saline } \\
\text { enema in intussusception reduction is high. } \\
\text { Delay in presentation decreases success of non- } \\
\text { operative treatment. Delayed enema reduction } \\
\text { is important therapeutic option for } \\
\text { intussusceptions. Surgical treatment is } \\
\text { indicated in cases of complications. }\end{array}$ \\
\hline $\begin{array}{l}\text { Beres et } \\
\text { al. }{ }^{(7)}\end{array}$ & Retrospective & Canada & $\begin{array}{l}\text { To compare outcome differences } \\
\text { after management of patients with } \\
\text { intussusception who either } \\
\text { followed the traditional hospital } \\
\text { admission pathway or were } \\
\text { discharged after a period of } \\
\text { observation in the ED } \\
\end{array}$ & 584 & 10 & $\begin{array}{l}\text { Pediatric intussusception can be safely } \\
\text { managed as an outpatient with reliable follow } \\
\text { up. Discharge from the ED reduces hospital } \\
\text { charges without increasing morbidity. This } \\
\text { approach should be considered in managing } \\
\text { patients with intussusception. }\end{array}$ \\
\hline$\underset{(8)}{\text { Ocal, et al. }}$ & Retrospective & Turkey & $\begin{array}{c}\text { To evaluate and } \\
\text { compare the demographic, } \\
\text { clinical and radiological } \\
\text { characteristics of cases with a } \\
\text { diagnosis of invagination } \\
\text { treated by manual reduction } \\
\text { (MR) with those treated by } \\
\text { Hydrostatic reduction (HR) }\end{array}$ & 72 & 2 & $\begin{array}{l}\text { HR together with USG is a safe technique in } \\
\text { the treatment of intussusception, which also } \\
\text { shortens the duration of hospitalisation and } \\
\text { significantly reduces the treatment costs }\end{array}$ \\
\hline $\begin{array}{l}\text { Sharp et } \\
\text { al. }{ }^{(9)}\end{array}$ & Retrospective & USA & $\begin{array}{c}\text { To compare between resection } \\
\text { and manual reduction outcomes } \\
\text { in treating } \\
\text { Intussusception }\end{array}$ & 111 & 11 & $\begin{array}{l}\text { Patients undergoing manual reduction have an } \\
\text { increased number of radiographic imaging } \\
\text { procedures. The surgeon should have a low } \\
\text { threshold for resection for intussusceptions } \\
\text { requiring operative management }\end{array}$ \\
\hline
\end{tabular}




\begin{tabular}{|c|c|c|c|c|c|c|}
\hline $\begin{array}{l}\text { Banapour } \\
\text { et al. }{ }^{(10)}\end{array}$ & Retrospective & USA & $\begin{array}{l}\text { To determine the characteristics } \\
\text { of older } \\
\text { children ( } 3-12 \text { years old) with } \\
\text { intussusception, and to } \\
\text { determine } \\
\text { how to best manage these } \\
\text { patients }\end{array}$ & 153 & 6 & $\begin{array}{l}\text { Children older than } 5 \text { years are much more } \\
\text { likely to have a pathological lead point and } \\
\text { early surgical intervention should be } \\
\text { considered. In this study, enema reduction was } \\
\text { safe but minimally beneficial in this age group }\end{array}$ \\
\hline$\underset{(11)}{\text { Lee et al. }}$ & Retrospective & Taiwan & $\begin{array}{l}\text { To assess the therapeutic value } \\
\text { of Gastrografin in the } \\
\text { management of ASBO in } \\
\text { children } \\
\text { after unsuccessful conservative } \\
\text { treatment } \\
\end{array}$ & 24 & 15 & $\begin{array}{l}\text { the use of a water-soluble contrast agent in } \\
\text { ASBO is safe in children and useful for } \\
\text { managing ASBO, particularly in reducing the } \\
\text { need for surgery when conservative treatment } \\
\text { fails }\end{array}$ \\
\hline $\begin{array}{l}\text { Nasir et } \\
\text { al. }{ }^{(12)}\end{array}$ & Retrospective & Nigeria & $\begin{array}{c}\text { To examine the safety } \\
\text { and effectiveness of non- } \\
\text { operative management in } \\
\text { ASBO } \\
\end{array}$ & 33 & 4 & $\begin{array}{l}\text { Non-operative management is still a safe and } \\
\text { preferred approach in selected patients with } \\
\text { ASBO. However, 53\% eventually required } \\
\text { surgery }\end{array}$ \\
\hline Li et al. ${ }^{(13)}$ & Retrospective & China & $\begin{array}{l}\text { To evaluate the feasibility of } \\
\text { and indication for laparoscopic } \\
\text { methods for neonates with } \\
\text { congenital } \\
\text { duodenal obstruction }\end{array}$ & 40 & 3 & $\begin{array}{l}\text { The laparoscopic methods can be performed in } \\
\text { neonates safely and are appropriate for a full- } \\
\text { term newborn. }\end{array}$ \\
\hline $\begin{array}{l}\text { Ooms et } \\
\text { al. }{ }^{(14)}\end{array}$ & Retrospective & Netherlands & $\begin{array}{l}\text { To analyze the outcome of } \\
\text { patients who had a correction } \\
\text { for intestinal malrotation after } \\
\text { the introduction of laparoscopy }\end{array}$ & 83 & 7 & $\begin{array}{l}\text { Laparoscopy should be considered } \\
\text { as a first approach to diagnose and } \\
\text { subsequently treat intestinal malrotation }\end{array}$ \\
\hline $\begin{array}{l}\text { Jensen et } \\
\text { al. }^{(15)}\end{array}$ & Retrospective & USA & $\begin{array}{l}\text { To see if laparoscopic repair of } \\
\text { congenital } \\
\text { duodenal obstruction could be } \\
\text { performed with similar } \\
\text { outcomes } \\
\text { to the traditional open repair }\end{array}$ & 64 & 6 & $\begin{array}{l}\text { Laparoscopic duodenoduodenostomy for } \\
\text { congenital duodenal obstruction is a technically } \\
\text { challenging procedure with a steep learning } \\
\text { curve. Despite a relatively high conversion } \\
\text { rate, clinical outcomes remained similar to the } \\
\text { traditional open repair in selected patients }\end{array}$ \\
\hline
\end{tabular}

Table 2: Intussusception studies' results' comparison.

\begin{tabular}{|c|c|c|c|c|c|}
\hline Study & Patients (n) & HR attempts (n) & HR success rate $(\%)$ & MR (\%) & Resection (\%) \\
\hline Vujovic et al. ${ }^{(6)}$ & 107 & 102 & $57 \%$ & $25.2 \%$ & $20.5 \%$ \\
\hline Beres et al. ${ }^{(7)}$ & 584 & all & $100 \%$ & \multicolumn{2}{|c|}{$1.5 \%$} \\
\hline Ocal et al. ${ }^{(8)}$ & 72 & 47 & $73 \%$ & $37.5 \%$ & $15.3 \%$ \\
\hline Sharp et al..$^{(9)}$ & 111 & - & - & $55.9 \%$ & $44.1 \%$ \\
\hline Banapour et al. ${ }^{(10)}$ & 153 & 130 & $52 \%$ & $33.3 \%$ & $18.9 \%$ \\
\hline Total & 927 & 863 & $70.5 \%$ & $30.5 \%$ & $19.9 \%$ \\
\hline
\end{tabular}

Table 3: Laparoscopic versus Open studies' results' comparison.

\begin{tabular}{|c|c|c|c|c|c|c|c|}
\hline Study & Patients (n) & Approach type & Patients (n) & $\begin{array}{c}\begin{array}{c}\text { Operation time } \\
\text { (minutes) }\end{array} \\
\end{array}$ & $\begin{array}{l}\text { Conversion rate (from } \\
\text { laparoscopic to open) }\end{array}$ & $\begin{array}{c}\text { Further subsequent } \\
\text { operations (Redo) }\end{array}$ & $\begin{array}{r}\text { Length Of } \\
\text { Stay (days) } \\
\end{array}$ \\
\hline \multirow{2}{*}{ Jensen et al. } & \multirow{2}{*}{64} & Laparoscopy & 20 & 145 & $35 \%$ & $10 \%$ & 20 \\
\hline & & Open & 44 & 96 & & & 30 \\
\hline \multirow[b]{2}{*}{ Ooms et al. } & \multirow[b]{2}{*}{83} & Laparoscopy & 33 & 63 & $45 \%$ & $17 \%$ (Redo only) & 9 \\
\hline & & Open & 50 & 76 & & $\begin{array}{l}14 \% \text { (ASBO and } \\
\text { Redo) }\end{array}$ & 16 \\
\hline Li et al. & 40 & Laparoscopy & 40 & 145 & $0 \%$ & $2.5 \%$ & 10.4 \\
\hline \multirow{2}{*}{ Total } & \multirow{2}{*}{187} & Laparoscopy & 93 & 117 & $26 \%$ & $10 \%$ & 13 \\
\hline & & Open & 94 & 86 & & & 23 \\
\hline
\end{tabular}

\section{Intussusception Studies: ${ }^{6-10}$}

Intussusception is a common abdominal emergency in early childhood. The treatment of choice is non-operative hydrostatic or air enema reduction. Vujovic $\boldsymbol{c}$ et al. ${ }^{(6)}$ evaluated the influence of clinical presentation and symptom duration in non-operative treatment, considering the indications for delayed enema reduction and its efficacy. This is a retrospective and partly prospective cross-sectional study of 107 children diagnosed with intussusception who were treated at the University Children's Hospital in Belgrade, during the period from 1995 to 2012. Successful treatment by hydrostatic saline enemas had 58/102 (57\%) patients. Success in reduction was greater if symptom duration was $<24$ hours $(87 \%)$, compared to $>24$ hours $(9 \%)$. Despite failed initial attempts, enema reduction was reattempted in 12 patients, with success in $(60 \%)$ of patients. Children with symptom duration $>24$ hours had 
a greater risk of requiring surgery $(91 \%)$, including $(5 \%)$ of patients with ileo-ileal intussusceptions.

Beres et al. ${ }^{(7)}$ compared outcome differences after management of patients to intussusception who either followed the traditional hospital admission pathway or were discharged after a period of observation in the ED. They also evaluated the potential cost savings related to early discharge. This was a retrospective review performed on all cases of intussusception that presented to two tertiary care pediatric hospitals in Canada between 2000 and 2010. 584 patient records were included in the study. 329 patients of them were managed with admission after reduction, and 239 as outpatients. In the admission group, $28(8.5 \%)$ patients had at least one recurrence, with 8 after discharge. In the outpatient group, 21 patients had at least one recurrence (8.8\%), with 19 after discharge. The difference post-discharge was significant. Outcomes of recurrence did not differ, with 2 patients in each group requiring operative intervention. Average length of stay in the admission group was $90 \mathrm{~h}$, with additional average cost of \$1771 per non-operated patient.

Ocal et $\boldsymbol{a l} .^{(8)}$ evaluated and compared the demographic, clinical and radiological characteristics of cases with a diagnosis of invagination treated by manual reduction (MR) with those treated by hydrostatic reduction (HR). This was a retrospective study done in 2014 in Sanliurfa, Turkey. They used records of 72 cases of intussusception treated between 2010 and 2012. Ultrasonography (USG) was applied to all cases on initial presentation. As treatment, HR together with USG was applied to 47 cases. Of these, the HR was unsuccessful in 13 cases. Surgical treatment was applied to 38 cases. Of these cases, ileocolic intussusception was observed in 30 cases, ileoileal in seven cases and colocolic in one case. Meckel diverticulum was determined in 5 of these cases, polyps in 2 cases, lymphoma in 2 cases, lymph nodule in 1 case and 28 cases were observed to be idiopathic. There was no mortality in any case.

Intussusception is most commonly managed with air-contrast reduction. However, when this fails, emergent operation with resection or manual reduction is indicated. Sharp et $\boldsymbol{a l} .^{(9)}$ compared between resection and manual reduction of intussusception regarding the outcomes. This was a retrospective review done on all patients who received operative care for intussusception from 2000 to 2012 in Children's Mercy Hospital, Kansas City, Missouri. The study included 111 patients. 49 of them underwent resection and 62 underwent manual reduction. Mean $( \pm \mathrm{SD})$ time to oral intake favored manual reduction $(2.1 \pm 1.2$ versus $2.6 \pm 1.2$ day, respectively). Manual reduction was associated with a greater need for repeat imaging (47\% versus 18\%) and the only recurrences were with manual reduction ( $8 \%$ versus $0 \%)$. Mean duration of stay was no different, nor was the need for reoperation.

Banapour et al. ${ }^{(10)}$ onducted a study to determine the characteristics of older children (3-12 years old) with ileocolic intussusception, to determine the incidence of pathological lead points and most importantly, to determine how to best manage these patients. This was a retrospective study collected all the records of intussusception in patients aged $<12$ years. The study was done in 2014 with a duration period of 7 years. They found that Ileocolic intussusception in 153 patients. 109 of them were $0-2$ years old, 34 were 3-5 years old, and 10 were 6-12 years. Bloody stools occurred in $42 / 143$ of $0-5$ years and $0 / 10$ of 6-12 years. Combined hydrostatic and/or surgical reduction was successful in $113 / 143$ of $0-5$ year olds vs $5 / 10$ of $6-12$ year olds. Enemas were safe but reduced only 1 patient over age 5 . Resections were required in 29 patients (15 idiopathic, 14 lead points). Lead points were found in $4 / 109$ children under 3 years, in 5/34 aged $3-5$ years and 5/10 aged 6-12 years. Lead points consisted of 7 Meckel's diverticula and 7 others.

\section{ASBO Studies ${ }^{(11-12)}$}

Lee et al. ${ }^{(11)}$ assessed the therapeutic value of Gastrografin in the management of adhesive smallbowel obstruction (ASBO) in children after unsuccessful conservative treatment. This was a retrospective review done in 2014 using medical records from patients with uncomplicated ASBO managed at Cathay General Hospital, Taipei, Taiwan between 1996 and 2012. All children were $\leq 18$ years of age with clinical evidence of ASBO were managed conservative treatment, unless there was suspicion of strangulation. Patients who did not improve after 48 hours of conservative treatment were administered Gastrografin.

24 patients with 33 episodes of ASBO were analyzed. 19 episodes of ASBO failed to respond to the initial conservative management. 16 of them (84\%) responded well to Gastrografin administration thereby abrogating the need for surgical intervention. There were neither complications nor mortality that could be attributed to the use of Gastrografin. 
Nasir et al. ${ }^{(12)}$ examined the safety and effectiveness of non-operative management in ASBO. This was a retrospective review of 33 patients who were admitted for ASBO over a 5-year period in University of Ilorin Teaching Hospital, Ilorin, Nigeria in 2012. They found that the median age of patients was 4.5 years. The major indications for a prior abdominal surgery leading to ASBO were typhoid intestinal perforation $(n=7)$, intussusception $(n=6)$, intestinal malrotation $(n=5)$, and appendicitis $(n=4)$ were the major indications for a prior abdominal surgery leading to ASBO. 25 patients $(73.5 \%)$ developed SBO due to adhesions within the first year of the primary procedure. Of the 34 patients admitted with ASBO, 18 (53\%) underwent operative intervention and 16 (47\%) were successfully managed non-operatively. There were no differences in sex, initial procedure, age, duration of symptoms, and time to readmission between the patients who responded to non-operative management and those who underwent operative intervention. However, the length of hospital stay was significantly shorter in the non-operative group.

\section{Congenital duodenal obstruction studies (Laparoscopic versus open): ${ }^{(13-15)}$}

Congenital duodenal obstruction is a common malformation in neonates. Li et al. ${ }^{(13)}$ evaluated the feasibility, and the indication for laparoscopic methods for neonates with congenital duodenal obstruction. This was a retrospective study done for a period of 3 years between 2009 and 2012. The study evaluated 40 newborn with duodenal obstruction underwent exploratory laparoscopy in Huai'an Women and Children's Hospital, Jiang $\mathrm{Su}$, China. Under laparoscopic vision, the causes of duodenal obstruction were diagnosed, and then the operation methods were determined by the type of obstruction. 4 of the 40 cases were duodenal atresia (type II), 8 were duodenal stenosis, 8 were annular pancreas, and 20 were congenital intestinal malrotation. All the different types of cases were approached and treated laparoscopically. Then, they were assessed throughout the admission for the post-operative outcomes.

Li et al. ${ }^{(13)}$ concluded that the laparoscopic procedure is an important method of diagnosing, and correct operational methods are the key to improve the therapeutic effect in the treatment of congenital duodenal obstruction. The laparoscope has the value of a small incision, micro-invasion, and better recovery in diagnosis and treatment for congenital duodenal obstruction.
Intestinal malrotation is a congenital intestinal rotation anomaly, which can be treated by either laparotomy or laparoscopy. Ooms et al. (14) analyzed the outcome of patients who had a correction for intestinal malrotation after the introduction of laparoscopy. This a retrospective study done in 2016 on all patients between 0 and 18 years who underwent a surgical procedure for malrotation in the Radboudumc Amalia Children's Hospital, Nijmegen, the Netherlands, between January 2004 and December 2011. 33 of 83 the included patients had a laparoscopic procedure and 50 had a laparotomy for suspected malrotation. They found significantly more complications in the laparotomy group. Length of hospital stay was significantly longer after a laparotomy. 3 patients in the laparoscopy group needed redo surgery compared with 6 in the laparotomy group. They concluded that in both the laparoscopy and laparotomy group, no cases of long-term recurrent volvulus were seen. After laparotomy, more patients developed a late small bowel obstruction because of the adhesions for which redo surgery was needed. In the laparotomy group, the number of complications was significantly higher and the length of hospital stay was significantly longer. Comparing laparoscopy and laparotomy for the treatment of malrotation, no difference exists for the long-term risk of recurrent volvulus. In children aged 6 months or older with suspicion of intestinal malrotation but not presenting with an acute abdomen or hemodynamically instability, laparoscopy should be considered as a first approach to diagnose and subsequently treat intestinal malrotation.

Jensen et $\boldsymbol{a l}^{(15)}$ compared between laparoscopic and open repair of congenital duodenal obstruction regarding comorbidities, operative details, and postoperative outcomes and complications. This is a retrospective review done in 2013. They reviewed medical records for all cases from 2005 to 2011 at three academic teaching hospitals in Los Angeles, California. 64 cases were included in the study. 44 of them were treated with open repair and 20 laparoscopically. Laparoscopic repair did take significantly longer than open repair (145 minutes versus 96 minutes, respectively), but clinical outcomes were similar. Complications were rare and were similar between the two methods of repair. Two patients in the laparoscopic group required subsequent open revision. 


\section{DISCUSSION}

Many different pathologic processes can cause pediatric intestinal obstructions. These processes can be presented as congenital intestinal obstruction or as acquired after birth ${ }^{(16)}$. We discussed some of these diseases and reviewed the latest studies that discussed and tackled the major controversies in intestinal obstruction management.

Intussusception is the most common cause of bowel obstruction in patients aged less than 2 years. The pathophysiology of intussusception happens when a part of the intestine slides into an adjacent part of the intestine. This telescoping can cause an intestinal obstruction with progressive mesenteric strangulation. Ischemia of the intestinal mucosa and venous stasis cause bleeding and mucous outpouring, that result in a red "currant jelly" stool ${ }^{(8)}$. Intussusception is diagnosed traditionally by USG. Ocal et al ${ }^{(8)}$ group retrospectively evaluated the presentation of the cases of intussusception and what are the signs and symptoms that present commonly ${ }^{(8)}$. They found that the findings on presentation were general discomfort, abdominal pain, distension and bloody stool (red currant jelly stool). They used USG as the diagnostic method of intussusception. It is nearly $100 \%$ sensitive and specific in diagnosis ${ }^{(8)}$. It showed the target sign of intestinal telescoping or invagination, also known as the doughnut sign or bull's eye sign. USG is not only diagnostic approach. It is used at the same time for treatment purposes on suitable cases. The success rate of HR in Ocal et al. ${ }^{(8)}$ paper was $73 \%$. So, the attempt at HR would seem to have evident superiority over MR rates. Also, because morbidity and mortality rates that were associated with anesthesia and surgery in the surgical type of intervention ${ }^{(6)}$. Vujovic et al. ${ }^{(6)}$ claimed the same conclusion and encouraged the HR even more than once. In their paper, they studied the influence of symptoms duration on the success of the non-surgical treatment ${ }^{(6)}$. HR was performed with successful reduction in $57 \%$ of patients, $93 \%$ from the group with symptom duration <24 hours, and only $7 \%$ with symptom duration $>24$ hours. Despite failed prior attempts, delayed enema was repeated in 12 patients with partial reduction initially, all from the group with symptom duration <24 hours, who were in a good general condition, with success in 7 of $12(60 \%)$ patients. The rest of patients (46\%) were still required surgical treatment without any reattempt of delayed enema, because of their severely disturbed condition. Therefore, Delayed repeated enema could be the second therapeutic option in the management of intussusceptions. The success rate of delayed repeated enemas was highest when there was initially a partial reduction of intussusceptum. It appeared that there was no fixed optimal timing between attempts because success can be achieved with a great variability of intervals. So, delayed repeated enema was highly advised but on the other hand there are obviously some exceptions in the cases of long duration of symptoms, especially if over 48 hours, significant bleeding and dehydration, obstruction of the small intestine or absence of blood flow at Doppler ultrasonography ${ }^{(6)}$. There were also other factors that affect the success rate of HR such as the child's age ${ }^{(10)}$. Banapour et al. ${ }^{(10)}$ group conducted a study to determine the efficacy and the safety of HR in older children (6-12 years old) and compare them with younger group (0-5). They found that children older than 5 years are significantly less respondent to HR. So, early surgical intervention should be considered and they concluded that enema reduction is safe but minimally beneficial in this age group ${ }^{(10)}$.

After the surgical consultation and intervention in $\mathrm{ED}$, physicians usually start to coordinate the management as in-patient and arrange for subsequent admission and observation ${ }^{(7)}$. On the contrary, Beres et $\boldsymbol{a l} .{ }^{(7)}$ group hypothesised that pediatric intussusception could be managed with discharge from the emergency department after successful reduction without increasing morbidity, potentially yielding significant health care cost savings. They studied records of 584 patients and compared between two groups of patients. One was managed with admission after reduction, and the other one was managed as outpatients. Outcomes of recurrence did not differ as 2 patients in each group requiring operative intervention. Average LOS in the admission group was $90 \mathrm{~h}$, with additional average cost of $\$ 1771$ per non-operated patient. They concluded that intussusception can be safely managed as an outpatient with reliable follow up like if the family are reliable to observe the patient well, or if they do not live far away from any hospital. Discharge from the ED reduces hospital charges without increasing morbidity and this economical cost effective approach should be considered in managing patients with uncomplicated intussusception $^{(7)}$.

Sharp et al. ${ }^{(9)}$ group evaluated the outcomes of the surgical management of intussusception and compared between resection and manual reduction. They found that Patients undergoing bowel resection for intussusception have significantly increased time to go back to regular diet, return of bowel function, and increased overall length of stay more than those 
undergoing manual reduction. However, manual reduction was associated with increased utilization of postoperative imaging, and the only recurrences occurred in this group (8\%). They suggested that surgeons should not maintain a high threshold for resection when facing injured bowel after reduction in order to minimize the risks of recurrence, perforation, and the need for additional postoperative imaging ${ }^{(9)}$.

By looking at table 2, we can sum up the intussusception management with that HR should be considered as first line treatment in uncomplicated cases even if it was tried more than once because it showed success rate of $70.5 \%$ putting in mind that subsequently there is $50 \%$ possibility to move to the operative management in case of failure or presence of complications. Regarding operative management, MR showed better postoperative cost effective results than bowel resection. On the other hand, MR showed higher possibility of recurrence and further complications like perforation. So, the surgeons should not lower their threshold for resection when they see injured bowe ${ }^{(9)}$.

The surgical intervention in treating intussusception can sometimes lead to subsequent complications such as adhesive small bowel obstruction $(\mathrm{ASBO})^{(11,12)}$. It is not only a complication of intussusception repair. It is a feared complication also after any abdominal operation in both children and adults. It is caused by the process of tissue healing and repair that happen after multiple injuries to the peritoneum. This problematic repair starts from the inflammation that might have been disrupted the normal anatomy to the formation of new tissue that may be an adhesion at last. These intra-abdominal adhesions are like bands that disturb the anatomy of the intestines. They may cause a huge reduction of the bowel caliber or they may cause strangulation that may lead to significant intestinal obstruction and subsequently perforation ${ }^{(11,12)}$.

In Nasir et al. ${ }^{(12)}$ paper, typhoid intestinal perforation were the most common indication for a prior abdominal surgery that led to ASBO. Nonetheless, the rate of adhesion-related readmission was higher following surgery for intestinal malrotation $(42 \%)$ and intussusception $(10.7 \%)^{(12)}$. On the other hand, Lee et al. ${ }^{(11)}$ paper's results showed that Appendicitis and Hirschsprung's disease are the commonest conditions that were the cause of surgeries in ASBO patients ${ }^{(11)}$.

Gastrografin (Diatrizoate megluminediatrizoate sodium) is very commonly used in cases of ASBO. Its main mechanism of action is by activating the movement of water into the small bowel lumen by osmosis and decreasing edema of the small bowel wall. It probably also enhances smooth muscle contractile activity. The combination of these effects is thought to generate effective peristalsis, enabling the small bowel to overcome ASBO. However, the diagnostic and therapeutic benefits of it in pediatric patients with ASBO are still controversial. So, Lee et al. ${ }^{(11)}$ group tackled this debate with a study conducted to assess the therapeutic value of Gastrografin in the management of ASBO in children after unsuccessful conservative treatment. They found that $84 \%$, of the patients that did not respond to the initial conservative management, responded well to Gastrografin administration thereby. This resulted in abrogating the need for surgical intervention. They added that there were neither complications nor mortality that could be attributed to the use of Gastrografin. Also, Nasir et al. ${ }^{(12)}$ group showed results that encourage non operative management initially. They conducted a study on 34 patients admitted with ASBO, 18 (53\%) underwent operative intervention and $16(47 \%)$ were successfully managed non-operatively. Both groups' outcomes were nearly similar. However, the length of hospital stay was significantly shorter in the non-operative group. Therefore, non-operative management is still a safe, cost-effective and preferred approach in selected patients with ASBO. Nevertheless, there is still more than $50 \%$ probability of moving to the operative management ${ }^{(12)}$.

Intussusception and ASBO are considered as acquired causes of intestinal obstruction. There are another type of intestinal obstruction which is congenital. Examples of congenital causes include duodenal atresia, malrotation, prenatal intestinal perforation, meconium ileus, Hirschsprung's disease. It has been reported that duodenal atresia and stenosis have a combined incidence of 1 in 7000 live births14. Furthermore, duodenal obstructions are often complicated by prematurity and associated anomalies ${ }^{(13)}$. Li et al. ${ }^{(13)}$ group conducted a study on 40 cases of congenital duodenal obstruction. First, they performed exploratory laparoscopy. They found 4 were duodenal atresia (type II), 8 were duodenal stenosis, 8 were annular pancreas, and $20(50 \%)$ were congenital intestinal malrotation. Then, they performed for each condition a different operation. The purpose of the study to evaluate the laparoscopic approach in such cases. They concluded that the laparoscope has the value of a small incision, microinvasion, and better recovery in diagnosis and treatment for congenital duodenal obstruction ${ }^{(13)}$. They also added that laparoscopic methods can be performed in neonates safely and are appropriate for a full-term newborn with tolerance to $\mathrm{CO} 2$ pneumoperitoneum. Jensen et al. ${ }^{(15)}$ 
group did a comparison study between laparoscopic and open surgery in the treatment of congenital duodenal obstruction regarding the outcomes. They said laparoscopic duodenoduodenostomy for congenital duodenal obstruction can be safely applied with similar outcomes to traditional open repair. The laproscopic procedure has better outcomes regarding decreased postoperative pain and improved wound cosmesis. On the contrary, it has some disadvantages like the difficulty in performing it and the long duration of operating time if we compared it with the open approach. Jensen et al. ${ }^{(15)}$ group emphasized as well on the steep learning curve of laparoscopic skills among surgeons as one of the major disadvantages. On the other hand, another study like Ooms et

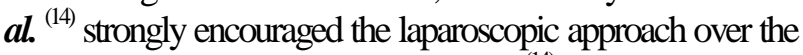
open in cases like congenital malrotation ${ }^{(14)}$. They compared 2 groups of patients treated with the 2 different approached and analyzed the outcomes of every case. They found that laparotomy and laparoscopy have nearly similar efficacy in treating the condition. However, laparotomy group experienced more complications like increased length of stay and development of intra-abdominal adhesions which caused later on ASBO that needed another surgery afterwards ${ }^{(14)}$.

\section{LIMITATIONS AND STRENGTHS}

The number of the included studies was large which provided us a broad spectrum of results and points to discuss. We covered high number of controversies and debates. During the selection, we double-reviewed the studies and we made sure that the studies we included are fit to be considered as major study, despite some of them were finalized upon small sample size which might provide bias to the review.

\section{CONCLUSION}

The success rate of Hydrostatic enema (HR) in intussusception reduction is high although this rate decreases if the case presented late. Repeated attempts of enema reduction showed relatively good results in the avoiding the surgical management of intussusception. With reliable follow up, intussusception can be safely discharge from the ED and managed as an outpatient after successful HR without increasing morbidity. Surgical treatment is indicated mostly in cases of complications. Manual reduction was associated with significantly better post-operative outcomes and lesser time to recovery. It is advised not to maintain high threshold for resection in order to avoid post-operative recurrence or perforation. The use of Gastrografin in treating children with ASBO when the conservative management fails is safe. However, half of the patients will need surgical management after all. The laparoscopic approach in the management of congenital duodenal obstruction can be performed in neonates safely. It showed similar outcomes to the open approach despite the presence of high conversion rate.

\section{REFERENCES}

1. Hucl T (2013): Acute GI obstruction. Best Pract Res Clin Gastroenterol., 27(5):691-707.

2. Zielinski M, Bannon M (2011): Current Management of Small Bowel Obstruction. Advances in surgery, 45(1):1-29.

3. Wright HK, O'Brien JJ, Tilson MD (1971): Water absorption in experimental closed segment obstruction of the ileum in man. Am J Surg., 121(1):96-99.

4. Wangensteen OH (1978): Understanding the bowel obstruction problem. Am J Surg., 135(2):131-149.

5. Rana SV, Bhardwaj SB (2008): Small intestinal bacterial overgrowth. Scand J Gastroenterol., 43(9):1030-1037.

6. Vujovic DR, Marija L, Sretenovic A et al. (2014): Indications for Repeated Enema Reduction of Intussusception in Children. Srpski Arhiv Za Celokupno Lekarstvo, 142(5-6): 320-24.

7. Beres A, Baird R, Fung E et al. (2014): Comparative Outcome Analysis of the Management of Pediatric Intussusception with or without Surgical Admission. Journal of Pediatric Surgery, 49(5): 750-52.

8. Ocal S, Muaze Z, Boleken M et al. (2014): A Comparison of Manual versus Hydrostatic Reduction in Children with Intussusception: Single-center Experience. African Journal of Paediatric Surgery, 11(2): 184-193.

9. Sharp N, Marty E, Corey W et al. (2013): Clinical Outcomes following Bowel Resection versus Reduction of Intussusception. Journal of Surgical Research, 184(1):388-91.

10. Banapou P, Sydorak R, Shaul D (2015): Surgical Approach to Intussusception in Older Children: Influence of Lead Points. Journal of Pediatric Surgery, 50(4): 647-650. 
11. Lee CY, Hung $M$, Lin $L$ et al. (2015): Evaluation of a Water-soluble Contrast Agent for the Conservative Management of Adhesive Small Bowel Obstruction in Pediatric Patients. Journal of Pediatric Surgery, 50(4): 581-85.

12. Nasir A, Abdur-Rahman L, Bamigbola $K$ et al. (2013): Is Non-operative Management Still Justified in the Treatment of Adhesive Small Bowel Obstruction in Children?. African Journal of Paediatric Surgery,10(3): 259-264.

13. Li B, Chen W, Zhou W (2013): Laparoscopic Methods in the Treatment of Congenital Duodenal Obstruction for Neonates. Journal of Laparoendoscopic \& Advanced Surgical Techniques, 23(10): 881-884.
14. Ooms N, Matthyssens L, Jos Draaisma J et al. (2013): Laparoscopic Treatment of Intestinal Malrotation in Children. European Journal of Pediatric Surgery, 26(4):376-381.

15. Jensen A, Short S, Anselmo D et al. (2013): Laparoscopic Versus Open Treatment of Congenital Duodenal Obstruction: Multicenter Short-Term Outcomes Analysis. Journal of Laparoendoscopic \& Advanced Surgical Techniques, 23(10):876-880. 